\title{
Influence: Getting Into the Zone on Demand
}

\author{
James S. Payne ${ }^{1}$ \\ ${ }^{1}$ The University of Mississippi, Oxford, Mississippi, USA \\ Correspondence: James S. Payne, The University of Mississippi, Oxford, Mississippi, USA.
}

Received: May 14, 2020

doi:10.20849/aes.v5i1.756
Accepted: June 24, 2020

Online Published: July 6, 2020

URL: https://doi.org/10.20849/aes.v5i1.756

\begin{abstract}
By learning how to teach 'grit' and creating the concept 'prelive' it is now possible to teach how to get into the zone on demand. A group of 24 second graders were taught how to work a Rubik's Cube. Ten students mastered the cube and all continued to work the cube for the entire academic year. During this process it was learned how to teach 'grit' through perseverance.

While learning how confidence is developed in business executives, salespersons and athletes the concept of 'prelive' was developed. 'Prelive' is a way to activate the brain in believing an event or task has been successfully executed before it has actually happened. When an individual imagines a positive result has happened to such a degree of intensity, before it has happened, the individual, at times, may experience zoneness which results in superior performance.
\end{abstract}

A sequence of events leading to zoneness is presented, illustrating pedagogical best practices for teaching how to get into the zone on demand.

Keywords: zone, flow, grit, deliberate practice

As one trains the body, it unquestionably affects the brain. But by reversing the process, as one train's the brain, it unquestionably affects the body.

\section{Introduction}

Instruments exist that somewhat accurately measure the activation impulses of the brain. Simply stated, electrodes that measure electrical currents (brain waves) are attached to the outside of the head. These instruments provide information that suggests in most, most of the time, the activation in the brain is scattered. However, when a person begins to concentrate or focus on something with some degree of intensity, the activation of the brain becomes more localized. When concentration or focus becomes more intense the activation becomes more pinpointed.

Amy Haufler and Bradley Hatfield, well known brain researchers, studied skilled and novice rifle shooters (Glover, 1998). By placing electrodes on the skull, they measured brain waves simultaneously with the accuracy of the rifle shots. They found novice shooters' brain activation is scattered, skilled shooter's brain activation is localized and in Olympian shooters, five seconds before trigger pull, the firing of the brain is even more pinpointed, indicating superior focus and concentration. Just by simply showing the shooters how brain activation relates to the accuracy of the shots, improvement in shooting is realized.

The brain is complex and there is confusion and disagreement on how the brain works. But most neuroscientists and brain researchers agree on three points:

1. Emotion plays a major role on the impact of the brain.

2. The brain is physiologically affected by the environment.

3. The brain can't tell the difference from fact or fiction.

Emotion:

Joseph LeDoux (1996) and Daniel Goleman (1995) helped us understand the role of emotion in learning. Simply stated, the stronger the emotion connected with the experience, the stronger the memory of the experience. When emotion is added to the learning, the brain deems the information important and retention is increased.

Physiological Change: 
Marian Diamond and Janet Hopson (1998) introduced the concept of 'neural plasticity.' Neural plasticity is the brain's ability to constantly change its structure and function in response to external experiences. The brain is similar to a muscle; you can change its shape by making it work.

\section{Fact from Fiction:}

One of the most unique findings of brain science is that the activation of the brain is the same whether it is imagined or real. This simple finding provides us with an abundance of opportunities and options for assisting brain development.

Take a moment to look at the ACTION and REACTION chains. Notice as the links in both the ACTION and REACTION chains evolve, there is an automatic, instinctive interaction between the two. As the ying and yang between the two connect, skill development and performance increase.

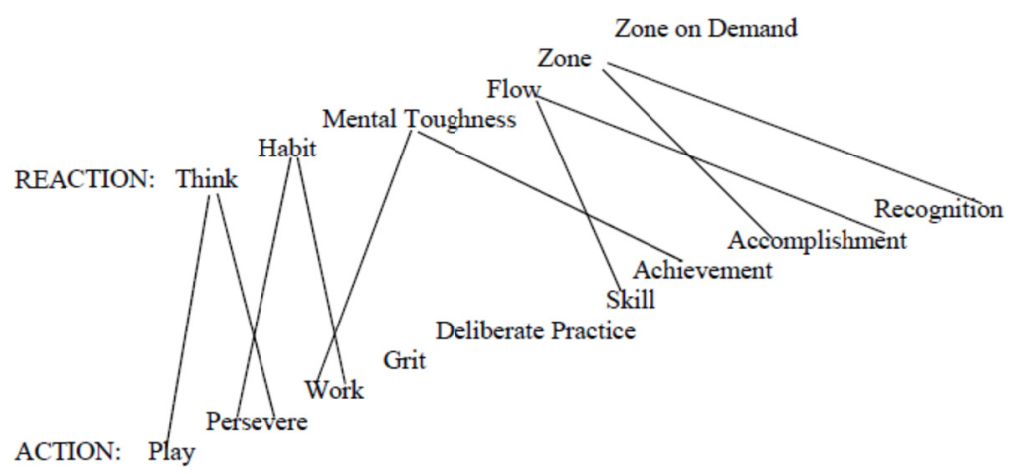

Figure 1. Interaction of action and reaction chains

\section{Model}

As an individual moves along the ACTION chain, things happen to the brain. Sometimes the links in the ACTION chain affect brain function on the REACTION chain and sometimes the brain function on the REACTION chain affects the links in the ACTION chain. We know as an individual moves along the ACTION chain the brain is very active. And, now we know ways to help and guide brain activity that, in turn, influences performance.

As one plays or starts to learn something, the brain goes through a trial and error process. It tries to figure things out. PLAY on the ACTION chain relates to THINK on the REACTION chain.

Through the thinking process, the learner dreams and envisions things. This fires up the brain which begins to shape or alter its structure and function. By providing things we have control over, like time to play and presenting opportunities to learn, we hope to influence brain growth. Ronald Kotulak (1996) uses a metaphor of a banquet to illustrate the interaction of the brain and the environment.

The brain gobbles up the external environment through its sensory system and then reassembles the digested world in the form of trillions of connections which are constantly growing or dying, becoming stronger or weaker depending on the richness of the banquet. (p.4)

By feeding the brain nutritious, environmental food and supplying a steady stream of environmental vitamins, the brain grows.

Since the brain is essentially curious, we can help it make the connection between the known and the unknown. We did this with second graders by teaching them how to work a Rubik's cube. By breaking the tasks down into tiny, understandable and relevant steps like, placing the cube on the table to keep it from turning, screwing a lid on a jar to teach clockwise and counterclockwise and realizing the left side of the cube is never used so focus on the sides used - front, right, bottom.

The relationship between the ACTION and REACTION chains is inevitable, but we don't have control over thinking. We can try to influence thinking by doing things we have control over. I don't have control over someone's thinking but I have $100 \%$ control of things I can do in hopes to influence thinking. 


\subsection{Play, Think, Persevere, Habit}

Play stimulates Thinking and Thinking stimulates Play. As Play continues, Perseverance sets in and when Perseverance continues, the Play activities become Work. Work can be enjoyable, unenjoyable or just plain Work but when Perseverance and Work connect, Habits are often formed.

Habits are learned functions and take over automatically; tying shoelaces, walking, speaking, memorizing, driving, riding a bicycle, adding, subtracting, multiplying, dividing, reading, working a computer, etc. The word "habit" originally meant garment or clothing. This gives us an insight into the true meaning of habit. Our habits are literally garments worn by us. They fit us and overtime become a part of us.

Habits can be helpful or not helpful. They can be good or bad. Through repetition, habits are formed. Habits are acquired behaviors and can be learned, unlearned, modified or changed. Most habits are formed by environmental influences like parents, teachers, coaches, counselors, ministers, and/or managers; teaching, telling or insisting, we do something over and over. We are told, reminded, praised when we do it and reprimanded when we don't.

When a bad habit develops and the individual wants to modify or change it they try to consciously force themselves to stop or change what they are doing.

It is possible to attack a bad habit or encourage the development of a good habit by focusing directly on the mental aspects of the habit. Since a habit is a part of us it forms a self-picture of who we are. Everyone has a mental picture of who they are and act in accordance with who they believe they are.

Let's say a person develops the habit of not remembering their keys. They have developed a mental picture that they can't remember where they place their keys. Dealing with the problem on the ACTION chain they can designate a place to put the keys, a special hook or bowl. Some people that have trouble remembering their keys attach to the key chain something big or something novel to make it easier to find.

To resolve the problem using the REACTION chain the person can change their picture of forgetfulness or not remembering to being smart, thoughtful and mentally tough. They form a different picture by repeating affirmations. "I am smart. My mind is like a memory vault. I see myself remembering my keys. I feel excited when I get my keys. Keys are a part of my very being."

The affirmations are repeated in the morning and in the evening when going to bed. Once the picture of remembering the keys replaces the picture of being forgetful, a new habit is formed not only for remembering keys but remembering names and other stuff.

The process of changing one's picture is explained in detail when covering the link, MENTAL TOUGHNESS on the REACTION chain. The technique is powerful and focuses directly on influencing the activation of neurons in the brain.

You start to learn a physical skill through trial and error. You usually learn a few basics, then you practice, practice, practice. As you get better, it becomes a habit. The habit is predominantly controlling the learned function of the subconscious. What separates the good player from the excellent player is mostly mental. The excellent player doesn't let failure bother them and they can't be influenced by outside negativity.

A habit is formed by transferring the thinking process from the conscious part of the brain to the subconscious part. Consider the interaction and role of the conscious and subconscious when catching a ball. Now elevate the complexity by catching the ball while running. Now distract the player by having people yell and scream. Finally, fill the subconscious with degrading comments to the point the player believes they are of little worth, are unsuccessful and can't do anything right. It is impossible to control the players thinking but there are things we have control over that might influence not only skill development in catching but develop a positive belief in self that will increase the skill of catching the ball.

Things we have control of on the ACTION chain are encouragement, praise, good instructions and multiple throwing to catch the ball. Control on the REACTION chain could be using affirmations in hopes to influence a positive picture.

\subsection{Work, Grit}

Let's take a moment to examine the difference between Work and Grit. On the ACTION chain both grow out of Perseverance but you can have Work without Grit but you can't have Grit without Work. Both require Perseverance and both produce Habits.

The major difference is Grit requires hurt, discomfort, pain. Work may get uncomfortable but Grit gets 
downright nasty. My dad delivered milk for 30 years. He got up at 5:00am, reported to work, iced and loaded the wagon hitched the horses and ran the route. I don't remember him missing a day and I don't remember him complaining. He did his job to put bread on the table for his family. He may have had grit but delivering milk for 30 years isn't what made him gritty. In addition to being a milkman, he was a body builder and every night he lifted weights. He had the burn. He would force himself to hurt and his body was solid as a rock. Lifting weights and working out is what made him a grit master.

A hard workout creates changes in the body. Certain muscles and the cardiovascular system are pushed to the point where homeostasis can no longer be maintained. Through hard exercise new capillaries grow and more oxygen is provided to the muscle cells so the body can return to the comfort zone.

This is how the body's desire for homeostasis can be harnessed to build the body. Pushing hard and long enough will reap a stronger, more coordinated body with greater endurance. So to have Grit, you have to push yourself to the limit for a long time. There are no easy shortcuts to Grit.

We have a pretty good handle on how the body responds to physical activity. We know much less about how the brain changes in response to mental challenges. A major difference between the body and the brain is that brain cells do not divide and form new brain cells. Instead the brain rewires networks, various connections between neurons are added and some are gotten rid of. Also, as concentration and focus increase the activation gets more localized.

Grit is formed through dissonance. Without dissonance there can be no Grit.

\subsection{Mental Toughness}

When an individual commits themselves to Deliberate Practice on the ACTION chain, the brain fires so often and with such velocity Mental Toughness automatically develops on the REACTION chain. Mental Toughness is developed from a combination of Perseverance, Work and Grit.

As the gritsy person, through Deliberate Practice, gets Mentally Tough, myelin is formed around the neurons of the brain, which enhance performance.

Myelin is a neural insulator that surrounds nerve fibers similar to the way rubber insulation wraps around a copper wire, making the signal stronger and faster by preventing the electrical impulses from leaking out (Coyle, 2009). "The thicker the myelin gets, the better it insulates, and the faster and more accurate our movements and thoughts become." (p.5). Ericsson and Pool (2016) indicate:

Myelination can increase the speed of nerve impulses by as much as ten times. Because these networks of neurons are responsible for thought, memories, controlling movement, interpreting sensory signals, and all other functions of the brain, rewiring and speeding up these networks can make it possible to do various things. (p.4)

Neuroscientists generally agree that myelin is built up through deliberate purposeful practice that is thoughtful and focused. It must be repetitious, challenging, and continuously move the individual out of the comfort zone but not so far out the individual quits.

The structure and function of the brain change in response to intense mental training, in much the same way your muscles and cardiovascular system respond to physical training. Using magnetic resonance imaging (MRI), neuroscientists have begun to study how the brains of people with particular skills differ from the brains of people without those skills. It is concluded skilled people have more myelin than unskilled people.

Myelin develops as an individual practices in deliberate, purposeful ways. But myelin can also be influenced through the technique of visual imagery and mental rehearsal.

The foundation for understanding visual imagery and mental rehearsal come from the seminal works of three great motivational experts: Maxwell Maltz (1967), author of Psycho-Cybernetics, Denis Waitley (1983), author Seeds of Greatness, and Louis Tice (1989), author of A Better World, A Better You. These bestselling masterpieces, written by these three scholars, have not only popularized the mental aspects of performance, they have operationalized it so it can be learned and taught.

The understanding of the mental aspects of visual imagery and mental rehearsal is simple but mastering it takes great discipline. Notice it takes discipline not practice.

Visual imagery and mental rehearsal are built on two concepts: mental picture of oneself commonly referred to as the Comfort Zone and the Creative Subconscious.

The Comfort Zone is so very powerful it locks us into acting and behaving as we see ourselves and believe ourselves to be. We act and behave in accordance with our picture. Our picture is our life's target. Our comfort 
zone is nothing more than a target of life. What keeps us on target, what keeps us functioning within our comfort zone, is the creative subconscious.

Maxwell Maltz (1967), a famous plastic surgeon and bestselling author, suggests the mind (creative subconscious) is like a homing system in a torpedo or an automatic pilot. Once the target is set, the self-adjusting mechanism guides the missile toward the target through a monitoring feedback system. This navigational guidance system constantly adjusts the flight of the missile by keeping it on target. Just as the propulsion of the missile drives it forward, the creative subconscious drives our behavior and actions. In other words, the creative subconscious is our motivator. The creative subconscious motivates us to perform within our comfort zone.

We cannot control the creative subconscious. The creative subconscious is always programmed to guide our behaviors and actions toward our picture, toward our comfort zone, toward our target. But the beauty is, we can move our picture, change our comfort zone, select a new target or refine an existing one. We can tell ourselves this over and over again, with such firm conviction, that we can actually see a new picture of ourselves, vividly, in high resolution. As we construct a new target of ourselves, the creative subconscious will drive us, monitor us, to become it.

You have the power to change or refine your target, but you cannot change or control the creative subconscious. The creative subconscious is nothing more than a homing device that drives your behaviors and actions toward the target.

Maxwell Maltz, Dennis Waitley, Louis Tice and others have created a sequence of steps for developing visual imagery and mental rehearsal that directly deal with improving performance by understanding how the comfort zone and creative subconscious work.

There are five basic steps to mastering visual imagery and mental rehearsal. As you master the steps you elevate your skill and performance.

\section{Picture What You Want, Not What You Don't Want}

This sounds simple, but you may find it isn't as simple as it appears. Often, we focus on what we don't want rather than on what we want.

Many times we focus on not embarrassing ourselves instead of seeing ourselves performing perfectly. We focus on the fact we don't want to fail instead of identifying success patterns. It is easy, and for some people very natural, to focus on what they don't want rather than what they want. The more positive and more clear the picture, the better.

\section{Imagine the End Result in Vivid Detail}

Once you get a picture of what you want, begin to perfect the image in the most vivid detail possible. The clarity of the picture in the highest resolution is the foundation of visual imagery and mental rehearsal.

You must create the picture in such a way you can see it, hear it, feel it, smell it, and taste it. The clearer and more focused the target, the more efficiently the tracking device of the creative subconscious will work. What motivates a person is not the picture; what motivates the person is the creative subconscious. If the picture is vague, the tracking device doesn't know exactly where to go, so it vacillates all over the place. When the picture is pinpointed, the tracking device is razor sharp.

\section{Engage in Self-Talk: Words, Picture, Emotion}

Self-talk takes on four characteristics: (a) First Person, (b) Present Tense, (c) Positive, and (d) Action-Emotion Oriented.

$>$ First Person: Start with "I." I like myself at 180 pounds. I am excited as I feel my clothes fit loose at 180 pounds.

$>$ Present tense: State it as of "now." Even though I might weigh 210 pounds, I see myself at 180 and I tell myself I am 180.

$>$ Positive: Put a positive spin on it. I see myself at 180 , not I want or need to lose 30 pounds. Stay away from negative thoughts like, I hate myself at 210 pounds.

$>$ Action-emotion oriented: Generate excitement and feeling. I see myself at 180 pounds, I feel my clothes fit loose at 180 pounds, I see people admiring me at 180 pounds, I feel light and carefree at 180 pounds, I feel people admiring my body at 180 pounds.

The idea is to use self-talk to motivate you to do what you are telling yourself to do or to be. The more emotional 
you can be and the more you can feel it, the more vivid the picture becomes. Self-talk enhances the development of the image or picture you are crafting.

\section{When Fail Flush}

If you do not occasionally fail, then probably you are not pushing yourself hard enough. When we do fail, we want to get back on track as soon as possible. Everyone has experienced a slump or a streak of bad luck. Why is it that if we fail once, we usually fail repeatedly? One of the major reasons is because it is so hard to get back on track. Once we fail, it is hard to get the failure out of our head. We mentally see the failure clearer than we envision success: The first step to getting back on track is to flush the failure out of our mind by using self-talk. Immediately after we fail, we tell ourselves, "That's not like me. That's not the Jim Payne I know." Then we follow this personal reprimand self-talk with positive self-talk, directing us toward our picture.

The rule of thumb is, if I continue to fail seven to ten trials or days, I should do something different, because my mind won't allow me to tell myself something I know is untrue. No one is forcing me to continue, so I will stop my self-talk. Before allowing myself to stop self-talk I move my goal closer. I am 210 pounds and I want to be 180 but I've gone 10 days and have even gained a pound. So I change my goal, "I like myself at 195. I see myself at 195. I see people admiring me at 195. I feel so fresh and alive at 195."

I must be careful not to create a false sense of hope. I can tell myself I want to be at 195 but I must know how to get there. I must know something about food, nutrition and exercise. I must have some knowledge and know-how otherwise I'm just kidding myself.

\section{Measure Outcome}

The last step is nothing more than a feedback or monitoring process that helps us keep on track. When possible, it is helpful if we can measure our progress objectively. This can be done in numbers or percentages. Most skill development can be measured as to accuracy, amount, length, speed, etc. Sometimes a vivid clear picture is selected that can't be measured objectively, so subjective judgment comes into play.

An example where judgment could be considered is improving one's ability to speak or improving an ability to interact with others. In these cases, it is necessary for us to get a feel for what we are doing in real life and if we think we are getting better, then we are, in fact, getting better. The beauty of using judgment is that we are the only ones we have to please. In addition to using our own judgment, sometimes we can monitor ourselves by videotaping or audiotaping our behavior or performance. If we are fortunate to have an objective friend that is knowledgeable as to what we are attempting to improve upon, we might find their comments helpful. The purpose of the feedback is to help the creative subconscious maneuver toward the target.

Say you are shooting a free throw in basketball, and you are doing well. All of a sudden, you shoot an air ball. When you get ready to shoot after the air ball, it is hard to get the bad shot out of your mind. You keep mentally seeing the ball missing the rim, and you imagine people laughing at you, so you try to consciously force or guide the shot. What has happened is the subconscious has taken hold of you and the only thing you think you can control is the conscious part of your brain. The subconscious always wins over the conscious. Same thing with golf. You miss a putt, and all of a sudden you get the "yips." You try to consciously guide or force the ball in the hole. It is all the same. The subconscious controls our behavior as we try to out-conscious the subconscious.

After years of being heavily engaged in DELIBERATE PRACTICE on the ACTION chain supported by MENTAL TOUGHNESS on the REACTION chain, superior skill develops that leads to ACHIEVEMENT, ACCOMPLISHMENT and RECOGNITION.

\subsection{Flow, Zone}

Advancing through the links of Achievement, Accomplishment and Recognition on the ACTION chain stimulates the links of Flow, Zone and ultimately Zone on Demand on the REACTION chain.

Mihaly Csikszentmihalyi (1998) has helped us understand the flow through his ideas about "the psychology of optimal experience." The flow is a state of mind in which people get so involved that nothing else matters. The experience is so joyful that they will continue in the activity over and over again even at great effort and/or sacrifice. When in the flow it is effortless, like being carried by a current. While experiencing the flow the activity is absorbing, interesting and fun. A mountain climber needs a goal of getting to the top. But the goal of getting to the top is nothing more than an excuse to climb. If there is not joy in climbing, then it is a wasted activity. The process is more important than the goal, although it is important to attain the goal. While in the flow, you transcend time and space; you get so caught up in the activity you lose track of time and you forget where you are. 
Abraham Maslow $(1968,1971)$, famous psychologist and author refers to a flow-like experience as having a peak experience. To explain a peak experience, he uses a Japanese Zen-based word 'muga.' A muga is a state of experiencing something wholeheartedly, totally without thinking of anything else, being without hesitation, inhibition, or fear.

When the experience of Flow is extended, the individual enters the Zone. Zoneness is knowing you are going to be successful before the task is executed. Not believing, not hoping, but actually knowing.

\section{Prelive}

During brain surgery, studies report that patients whose brain cells are stimulated with tiny electrodes describe "reliving" scenes from the past. Keep in mind, they are not remembering; they are "reliving" the experiences. When in the zone, you experience sensations that allow you to "prelive." In other words, you create the future rather than relive the past. When you "prelive," you experience an event wholeheartedly before it happens; you "will" it to happen. People that get into the "zone" are actually "preliving," that is, they are seeing, feeling and experiencing a future event before it happens. In other words, they create the future.

"Preliving" allows us to go beyond visual imagery and mental rehearsal through "preliving" we go directly to controlling the firing of the brain.

Mastering visual imagery and mental rehearsal techniques increases concentration and focus. By repeatedly seeing and imagining the successful result, the mind screens out distracting events and activities and sharpens attention and intention. By adding the concept of "preliving" to the equation of visual imagery and mental rehearsal, the activation of the brain intensifies and becomes more localized.

In basketball, after a free throw is converted, the brain activates, communicating what was accomplished was good and tells the body to do it again. Repeated conversions increase the activation and the activation becomes more localized, thus, the skill improves and repeats itself. Missed shots confuse the brain and make it go into a problem solving or search mode where the firing is scattered. So if during practice more shots are missed than successfully made, the brain gets confused and fires all over the place. It doesn't know what to tell the body to do. It may even get the body to do things that interfere with success.

When "preliving," the mind tells the body what to do before the shot is executed. In other words, the brain fires in the same way and location, before the task is executed, as it does after successful completion of the task. During "preliving" the brain actually thinks the task has been completed before it has actually happened because the brain can't tell fact from fiction: what actually happened from what was imagined to happen.

The brains of Olympians and other high performance individuals make the athlete believe they are going to be successful. This is where the confidence comes from. Through "preliving" the activation is so intense the athletes' progress from 'believing' they will be successful to 'knowing' they will be successful. They 'know' it because the brain has fired in such a way that the brain thinks the task has already been successfully completed.

Zoneness is when the athlete "knows' they are going to be successful. Mastering the techniques of "preliving" leads to being in the zone.

"Preliving" is being able to experience the joy and excitement prior to successful completion of the task. To help develop the skill of "preliving," every time we succeed and experience the joy, we force ourselves to take time and bask in the moment. We take a little time to let the brain process what has happened and what is going on in the brain. As the brain processes the feeling, it will help us "prelive" the feeling through imagining.

To teach a person how to "prelive," it helps to understand how a person learns and prefers to be taught.

Some people are more aggressive than others. While putting a golf ball, some players jam the ball in the back of the cup while others let it die in the hole. Some golfers approach their preshot routine for putting in a direct purposeful way while others take their time. Different people approach the same thing in different ways. One person wants to eat, the other wants to dine. One wants to buy, the other wants to shop. People have the same wants and needs, but their thinking and approaches to fulfilling those needs vary.

\subsection{Psychological Match}

To perfect the skill of "preliving," it is important to have a psychological match between how a person learns and how they want to be taught. Not everyone learns the same thing the same way. Most people have a good mixture or variety of ways they learn but also most people have a preferred way they want to be taught.

Through experience and observation, I have come to the conclusion there are three predominant ways to utilize "preliving" to increase concentration and focus that lead to getting into the Zone (Payne, 2004). Study each of 
the three techniques and if you can't decide on one that fits you, pick one, try it and if it doesn't work, try another. You will eventually experience superior results with one of the three.

The three techniques are classified in mindsets; directive, calculative and affective. The example of putting a golf ball is used to illustrate the techniques.

\subsubsection{Directive}

Words used to describe the 'Directive' mindset are: absolute thinking, order, discipline, strong work ethic, structure, linear sequencing and direct.

\section{SEE, PRELIVE, DO}

Your strength lies in perseveration, methodical approach, incremental steps, step-by-step process. You will use a SEE, PRELIVE, DO process.

You begin by placing the ball about where you are 60 percent successful, say, four to six feet from the hole. You grip the club exactly the way you want; you address the ball exactly the way you want; you look at the cup and then refocus on the ball. You imagine the ball dropping into the cup. You imagine hearing the plunk of the ball dropping into the bottom of the cup. At this point, you experience joy and a tingling sensation. After reveling in the imagined successful experience, you strike the ball. As the ball drops in, you get a double charge of emotion. When you miss, flush it out of your mind quickly and begin again. When you practice, make sure you are at a distance where you convert at least 60 percent of your putts.

It is very important that while practicing zoneness, you never get beyond the distance where your accuracy level falls below 60 percent. Your strength is in the repeated activation of your brain, which happens every time you hit your target. If you are at a distance that drops below 50 percent, you are confusing the brain.

In summary, you mentally SEE the ball go into the hole and mentally hear the plunk as it drops to the bottom of the cup, which sends joy throughout your body. The joy is PRELIVE, the tingling feeling, then you DO, by striking the ball. By experiencing the emotion before executing the skill, you will reap success that can be objectively determined by an increase in successful conversions.

\subsubsection{Calculative}

Words that describe individuals with a 'Calculative' mindset are: possibilities, cause and effect, multiplistic thinking, novel and calculating.

\section{TUBE, PRELIVE, DO}

Your strength lies in your cause and effect type of thinking and your intense drive to make a specific event happen. You will use a TUBE, PRELIVE, DO process.

To utilize the TUBE, PRELIVE, DO technique for putting, you place two ball markers eight inches from the cup the width of the cup. A ball placed six feet from the cup is now only five feet, four inches from the markers. You are tricking your mind into believing the hole is closer. You imagine the ball markers making an eight-inch tube to the hole. You imagine the ball going through the entrance of the tube; you hear the plunk, which makes you tingle with excitement, then you strike the ball. You will experience immediate success, and you will be tempted to move the ball further away from the hole. Don't. Stay at the six-foot distance with the markers eight inches from the hole and concentrate on experiencing the emotion prior to striking the ball.

Eventually you will be able to just imagine the markers. The physical placement of the markers is no longer needed. Beware you may get so good so fast, you forget to wait for the emotion, the PRELIVE, before striking the ball. The key to controlling the activation of the brain (getting into the zone) is feeling the excitement of converting the putt before the ball is struck.

What is the difference between the directive and calculative mindset approaches? The difference is the markers. Why can't the directive mindset use markers? Through observation and experience, the player with a directive mindset gets distracted by the markers, and immediately the percentage of conversions decrease.

Why does the player with the calculative mindset benefit from using markers? Without markers, the percentage of conversions plateaus. With markers, the percentage of conversions quickly increase.

People learn in different ways and different rates. By experimenting with both, you will discover what works best for you. Regardless of which one is decided upon, you must PRELIVE before executing the task.

\subsubsection{Affective}

Words that describe individuals with an 'Affective' mindset are: empathic, sensitive, sense-of-the-idea, 
feeling-for-the-task, and affect.

FEEL, SEE, PRELIVE, DO

Your strength lies in your sensitivity to others and the environment. You get a kick out of challenging yourself. You have abnormal touch and feel. By using the FEEL, SEE, PRELIVE, DO process you will learn to activate the neurons in your brain and thus influence the ball effectively.

You must first get intimately familiar with the club. Feel the grip as well as the head. Gently hold the putter high in the air with one hand, and with the other, take a metal object like a coin or car key and poke it at different places along the face of the putter. You will feel the putter twist and turn in your outstretched hand when you strike the putterhead outside the sweet spot. When you hit the sweet spot, the putter will feel solid, and it won't twist and turn in your hand. Before putting any balls to a hole, you must first be able to strike the ball on the sweet spot every time. Hitting the ball on the sweet spot will send a feeling of confidence through your hands and into your body. However, you want hitting the ball on the sweet spot to transfer to your brain. To get this feeling of successfully hitting the ball on the sweet spot, you merely tap the ball around the practice green, focusing on hitting the ball on the sweet spot. Do not try to knock the ball into a hole. Having an affective mindset, you will have no trouble finding the sweet spot, and you are so sensitive you will know immediately when you hit the ball on the sweet spot. Furthermore, you will get the knack of hitting the ball on the sweet spot within ten to fifteen minutes of concentrated practice.

As you get better and you feel what it is like to hit the ball on the sweet spot, begin to hit the ball harder until you are hitting it 20 to 30 feet. Now begin to lag the ball to a 10-foot line, but before striking the ball, FEEL what it is like mentally. SEE the ball come close to the lag line, PRELIVE the experience, the tingle, then DO strike the ball. As you gain confidence, place six balls in a circle three feet from the hole. As you putt, pile the balls up into the hole until it overflows. As the cup fills up and as it begins to overflow, you will become more excited, and you can't wait to do it again

At this point, you are controlling the activation of the brain; FEEL, SEE, PRELIVE, DO. FEEL the sweet spot. SEE the ball go into the hole. Mentally hear it plunk to the bottom of the cup. PRELIVE the tingle and DO strike one ball. Repeat the process until all six balls are putted. As you practice, always use six balls, and always put them in a circle around the cup. As you improve, increase the distance in six-inch increments. If you feel it might help, try listening to soft music while practicing putting.

It will take you a little longer to experience success, but your putting will become masterful within a reasonable period of time. The important thing is not to rush it. You have the mental makeup to be a masterful putter because the skill of putting is mostly feel and touch.

Let the brain work for you by using the FEEL, SEE, PRELIVE, DO process. For you, putting is feeling and touch, the rest is mental.

Why can't players with the directive and calculative mindsets use the affective mindset approach? My experience is, individuals with directive and calculative mindsets want results faster and lack the patience of taking the time to get the feel of the club. They want to get on with trying to put the ball in the cup. Using the affective mindset approach is a slow process and takes time and patience to just get started. Also the increase in the percentage of conversions is more gradual and less dynamic. Using anyone, or any combination, of the three techniques utilizing PRELIVE increases concentration and focus. The more times it is used and the more emotion injected into the process, the greater the opportunity of Flow being experienced. As Flow is experienced, Zoneness appears. Flow is primarily subconscious, and is a state of being, a state of experiencing the joy of the moment. As Zoneness emerges, Flow morphs from a subconscious act into a more conscious experience that empowers the individual to Achieve, Accomplish and be Recognized for greatness.

By injecting "prelive" into the visual imagery, mental rehearsal process, the firing of the brain becomes more intense and more focused. By using a technique for "preliving" that matches how the individual prefers to be taught, the activation of the brain fires with less effort and more times. The more intense the firing and the more times, results in the firing being more localized. Intensity, increase number of times, being more localized, overtime becomes pinpointed which accelerates the opportunities of Flow that lead to being in the Zone.

1. Prelive injected into Visual Imagery and Mental Rehearsal

2. Prelive taught the way the individual prefers to be taught

3. Flow emerges unconsciously

4. Zone creates a higher awareness giving abundant skill power 
PRELIVE increases confidence from 'believing' to 'knowing,' through 'knowing' you create ZONE on DEMAND.

\section{Conclusion}

A theoretical framework is presented showing the relationship between ACTION and REACTION. Examples are presented on how the process can be reversed where REACTION leads to ACTION. The purpose of the article is to present a model on how to get into the ZONE on DEMAND.

The key to learning how to get into the zone is PRELIVE. PRELIVE is a concept created by the author. When an individual 'prelives' an event before it happens, zoneness is created. Individuals that get into the zone are actually 'preliving' the experience before it happens.

Three methods are presented for getting into the zone by 'preliving'. They are Directive, Calculative and Affective.

\section{References}

Coyle, D. (2009). The talent code. NY: Random House, Inc.

Csikszentmihali, M. (1998). Finding flow: The psychology of engagement with everyday life. New York: Harper-Collins.

Diamond, M., \& Hopson, J. (1998). Magic trees of the mind: How to nurture your child's intelligence, creativity, and healthy emotions from birth through adolescence. New York: Penguin Putnam.

Ericsson, A., \& Pool, R. (2017). Peak: Secrets from the new science of expertise. NY: Houghton Mifflin Harcourt.

Glover, D. (1998). Math like you've never seen it before (videotape). Pittsburgh: WQED.

Goleman, D. (1995). Emotional intelligence: Why it can matter more than IQ. NY: Bantam.

Kotulak, R. (1996). Inside the brain: Revolutionary discoveries of how the mind works. Kansas City, MO: Andrews \& McMeely.

LeDoux, J. (1996). The emotional brain: The mysterious underpinnings of emotional life. New York: Simon \& Schuster.

Maltz, M. (1967). Pyscho-cybernetics. New York: Prentice Hall.

Maslow, A. H. (1968). Toward a psychology of being. Princeton, NJ: Van Nostrand.

Maslow, A. H. (1971). The farther reaches of human nature. New York: Viking Press.

Payne, J. (2004). PeopleWise brain to brain. Pittsburgh, PA: Sterling House Publisher, Inc.

Tice, L. E. (1989). A better world, a better you. New Jersey: Prentice Hall.

Waitley, D. (1983). Seeds of greatness. New York: Pocket Books.

\section{Copyrights}

Copyright for this article is retained by the author(s), with first publication rights granted to the journal.

This is an open-access article distributed under the terms and conditions of the Creative Commons Attribution license (http://creativecommons.org/licenses/by/4.0/). 